\title{
Reconnecting Health and Housing: Philanthropy's New Opportunity
}

\author{
David D. Fukuzawa and Fred Karnas
}

The connection between the health and dwelling of the population is the most important one that exists.

-Florence Nightingale (1820-1910)

Connections between health and housing for low income people need to be intentional. This doesn't happen by serendipity. _Michael Rubinger, quoted in the Wall Street Journal, January 13, 2013

\begin{abstract}
The connection between health and housing was widely understood by nineteenth century social reformers and philanthropists and was the dominant framework for low-income housing until the early twentieth century. The Affordable Care Act has not only set in motion reform in the nation's health care system, but also opens up new opportunities for re-connecting the housing and health sectors. While housing affordability will remain the central challenge for low- and middle-income people, the strong evidence of how housing quality and affordability impacts health calls for a new framework that envisions housing as a platform for improving quality of life. This platform can be conceived as a multi-layered: as service delivery portal, as target for prevention, and as anchor for healthy neighborhoods. These layers are associated with different at-risk populations and different strategies for financing and policy action. Philanthropy can play a key role in re-connecting the sectors through its capacity to build the evidence base, change the discourse about housing, foster policy change, and promote innovation.
\end{abstract}

$\mathbf{F}$ LORENCE Nightingale's OBSERVATION about the connection between health and housing would have found a receptive audience among her contemporaries. It reflected what had become a broadly shared view on both sides of the Atlantic towards the burgeoning tenements and slums of a rapidly urbanizing England and America. In America, waves of immigration increased the urban population from 300,000 in 1800 to 54 million by 1920 . The immigrant poor were housed in dark, crowded, unventilated, and unsanitary slums, which became hotbeds for major outbreaks of diseases such as cholera, typhus, small pox, and yellow fever. ${ }^{1}$

Mr. Fukuzawa is the managing director of the Kresge Foundation's Health program in Troy, Michigan. Mr. Karnas is a senior fellow at the Kresge Foundation in Troy, Michigan.

(C) The Author(s) 2015; Published by Mary Ann Liebert, Inc. This Open Access article is distributed under the terms of the Creative Commons License (http://creativecommons.org/licenses/by/4.0), which permits unrestricted use, distribution, and reproduction in any medium, provided the original work is properly credited.

${ }^{1}$ Howard Frumkin, Lawrence Frank, Richard Jackson, Urban Sprawl and Public Health: Designing, Planning, and Building for Healthy Communities (Island Press, 2004), 52-53; Lawrence Frank, Peter Engelke, Thomas Schmid, Health and Community Design: The Impact of the Built Environment on Physical Activity (Island Press, 2003), 12-13.
Middle class social reformers, including physicians, joined with philanthropists to mount a social movement to address the problem. Reformers led the fight to improve sanitation, ventilation, and other housing related conditions-efforts which led to the creation of the modern public health system. ${ }^{2}$ Philanthropists were instrumental in the creation of model tenements and "social housing." Both wealthy individuals and early industrialists helped build such housing for the growing factory working class, becoming a precursor for the public housing of the twentieth century. ${ }^{3}$

Reform efforts did not stop at housing amelioration, but also extended to direct charitable work and public policy. Much of the early charitable "caregiving" certainly reflected the paternalistic attitudes of reformers and philanthropists, who viewed the behavior of the poor as a defect of character, but also eventually gave rise to

\footnotetext{
${ }^{2}$ Russ Lopez, "Public Health, the APHA, and Urban Renewal," American Journal of Public Health 99 (Sept. 2009), 1603

${ }^{3}$ Peter Dreier, "Philanthropy and the Housing Crisis: The Dilemmas of Private Charity and Public Policy," Housing Policy Debate 8:1 (1997), 235-293, DOI: 10.1080/10511482.1997, 9521253, 239-240.
} 
the settlement house movement and the modern human services sector. The public policy reforms included not only new sanitary and public health regulations, but also regulation of the private housing market. ${ }^{4}$

In the 1920s this understanding of the housing-health connection, and alliance between public health and philanthropy on housing reform began to break down. And as the quote from Michael Rubinger of Local Initiatives Support Corporation (LISC) would suggest, the link that existed a century ago has been reduced now to "serendipity."

This article will discuss why the current time represents an opportunity to restore the link and therefore for philanthropy to re-think its approaches to low-income housing. While there are several key factors behind this possible restoration, none is perhaps as powerful as the Patient Protection and Affordable Care Act (ACA), signed into law in 2010.

It is important to remember that the ACA has several critical and broad purposes beyond closing the coverage gap for 30 million uninsured Americans. It also intends to foster deeper reforms and changes in the nation's health system aimed at improving quality and health and slowing health care spending's unsustainable rate of growth. Although the U.S. spends more per capita on health care than any other industrialized country, it ranks 26th in terms of life expectancy at birth. At $\$ 2.8$ trillion, health care consumes $17 \%$ of gross domestic product (GDP), and is projected to reach $\$ 4.1$ trillion in five years. ${ }^{5}$

Increasingly, health system leaders and experts recognize that significant savings will not come from medicine alone, but through addressing the social and environmental factors that lead to unhealthy lives and behaviors. Communities that have limited healthy food options or lack opportunities for physical activity, for example, have higher rates of obesity and diabetes. Further, research is reaching a critical mass, highlighting the impact of housing on health, and correspondingly, the cost savings that can result from smart investments in housing and housing-based interventions. ${ }^{6}$

To support our case, the article will: 1) briefly discuss further the roots of the housing-health divergence; 2) continue with an overview of current philanthropic investment in housing; 3) review the growing body of research and evidence about the multiple ways that housing impacts health; 4) describe how a reforming health care environment presents a significant opportunity to re-connect health and housing through a multilayered, housing-as-platform approach; 5) and describe new roles foundations can play in reconnecting health and housing.

\footnotetext{
${ }^{4}$ Dreier, 242

${ }^{5}$ OECD, Health at a Glance 2013: OECD Indicators (OECD Publishing, 2013), 25, < http://dx.doi.org/10.1787/health_glance 2013_en > ; < http://www.cms.gov/Research-Statistics-Data-andSystems/Statistics-Trends-and-Reports/NationalHealthExpend Data/downloads/proj2012.pdf > .

${ }^{6}$ See Commission to Build a Healthier America (Robert Wood Johnson Foundation, Feb. 2014).
}

\section{THE ROOTS OF THE DIVORCE: HOW HOUSING, HEALTH AND PHILANTHROPY DIVERGED}

Well before the Depression, reformers began to recognize the need for federal involvement in housing for the poor. When the Depression's impact reached Main Street America, the federal government quickly became the main driver of both housing development - through construction of public housing and private market subsidies-and of policy. Federal policy changes helped to stabilize the banking sector to free up lending for housing. The 1930s saw the creation of the Federal Housing Administration (FHA) and the Federal National Mortgage Association (Fannie Mae, 1934); and public housing for the poor and working class (Wagner Steagall Housing Act, 1937). Following World War II, the Housing Act of 1949 called for " a decent home and suitable living environment of every American family" and eventually set the framework for slum clearance, urban renewal, and expansion of public housing. ${ }^{7}$

During these decades of public sector activism, philanthropic investment in housing all but vanished, and housing policy became seen as largely the government's responsibility. Philanthropy's re-entry into housing came in the 1960s, through the Ford Foundation. But Ford's attention-principally through the Gray Areas Projectwas focused primarily on poverty alleviation and economic empowerment, and not on health. This effort, for example, supported community activism, including tenant organizing which led to strikes against slum landlords. One of Ford's most significant and enduring contributions during this period was its support for community development corporations (CDCs), which continue to be key drivers for development in lowincome communities. ${ }^{8}$

The 1980s marked a period of renewed philanthropic activism in housing, which Dreier sees as a response to the rise in homelessness. Larger changes in the economy, especially manufacturing, hit cities hard. Declining or stagnant incomes, rising rents and housing costs, a decrease in public assistance and subsidies, all contributed to a larger crisis in housing, especially for low-income individuals and families. There was also a continuing de-institutionalization of mental health hospitals. While motivated by humane reasons, de-institutionalizing mental health patients was not accompanied by an equal investment in the community infrastructure of housing and services needed to allow transitioned patients to live stably in the community. During the 1980 s, estimates of the homeless population ranged from 250,000 (Department

\footnotetext{
${ }^{7}$ J.A. Stoloff, “A Brief History of Public Housing," Paper presented at the Annual Meeting of the Sociological Association, San Francisco, 2004, 9-10, <http://reengageinc.org/ research/brief_history_public_housing.pdf > ; Dreier, 244.

${ }^{8}$ Dreier, 246; Alexis deRaadt St. James, "Can we Rebuild the Relationship between US Philanthropy and Affordable Housing," Rebuilding the Relationship between Affordable Housing and Philanthropy (Smith Institute, 2013), 84-89.
} 
of Housing and Urban Development, HUD) to 600,000 (Urban Institute) to over 3 million by some advocates. Whatever the actual number, it was becoming clear to many that the numbers were rising dramatically. ${ }^{9}$

The responses by foundations, according to Dreier, bore some resemblance to philanthropic investments of the earlier era: through services or caregiving (primarily support for shelters and homeless services); model housing (primarily nonprofit housing development); and public policy reform (including support for community and tenant advocacy, and other progressive social movements). But other than grants from two foundations - the Robert Wood Johnson Foundation and the Pew Memorial Trust-to establish coordinated health care services for the homeless, the bulk of philanthropic engagement in housing was a reaction to the crisis driven by poverty, decreasing federal support, and inadequate supply of decent, affordable housing. ${ }^{10}$ This continues to be the dominant framework for philanthropic investment in housing. It has been suggested that most funders come to housing in one of two ways: 1) through their commitment to individuals (e.g., asset building, preventing homelessness, closing gaps in health status); or 2) through an interest in places: housing options are seen as a key ingredient in community stability, in schools, and expanding economic opportunity. ${ }^{11}$

The Great Recession, which was triggered largely by the collapse of the sub-prime mortgage market, dramatically and tragically exposed the vulnerability of middleand low-income homeowners to housing insecurity and homelessness. It rippled into rental housing, sending prices higher. While almost all renters felt the impact, low-income renters were particularly hard hit. Today, one out of every four renters is an extremely low income (ELI) household (with annual incomes less than \$20,000) and $75 \%$ of those households spend at least half of their income on housing costs. With now over 10 million ELI households in the U.S., the average household can only afford to spend $\$ 493$ per month on housing. Given that the average Fair Market Rent in the U.S. for a twobedroom residence is $\$ 984$, it is easy to see why ELI households are forced to make hard choices between paying their rent, covering health care costs, or buying quality food. ${ }^{12}$

Philanthropic leaders took note of the crisis and called for action. Foundations also apparently matched their rhetoric with money, despite significant losses in their assets. An early analysis of foundation response to the financial crisis, based on a sampling of grants made from

\footnotetext{
${ }^{9}$ Dreier, 256-267; Martha Burt, "Homelessness: Definitions and Counts," Homelessness in America (ed. Jim Baumhol, Oryx Press, 1996).

${ }^{10}$ Dreier, 267-268.

${ }^{11}$ Rebecca Riley, M. Katherine Kraft, The Potential for Public-Private Partnerships: Philanthropic Leaders Considering Housing as a Platform, (What Works Collaborative, December 2010), <http://www.urban.org/publications/1001512 .html > .

${ }^{12}$ National Low Income Housing Coalition, Out of Reach 2014 (2014), <http://nlihc.org/sites/default/files/oor/2014OOR .pdf $>$.
}

2008 to 2010 , indicated that foundations "responded in a targeted and timely manner, with grants appropriately directed towards communities with the most need." The initial response was aimed largely at the immediate mortgage delinquency problem, but then shifted to the larger economic challenges, including unemployment. ${ }^{13}$

\section{HOUSING AND PHILANTHROPY TODAY ${ }^{14}$}

Our observation is that current philanthropic investment in housing goes beyond the historic triad of support for services, model housing, and policy reform. Due largely to the breadth of the housing sector and the systemic nature of the sector's challenges, funders have generally pursued more niche-driven strategies, rather than comprehensive. The exceptions to this have been the national housing industry-related funders like the Fannie Mae Foundation and one national, non-industry-related foundation, the MacArthur Foundation. Both have covered the waterfront of housing issues from research, to policy, to specific housing approaches or programs and direct investments in housing. It should be noted, however, that after a decade of significant contributions in this area, MacArthur has decided to shrink its broad efforts in the housing arena. Its departure follows that of the Fannie Mae Foundation, which closed its doors in 2007, and also the Freddie Mac Foundation, which began winding down its giving at that time, ultimately closing in 2014 .

The loss of these leading funders leaves a serious gap in the field, with few obvious successors. A hopeful sign perhaps is the entry of the J. Ronald Terwilliger Foundation for Housing America's Families, which was recently created to "work to better align public policies with housing needs.", 15

The more common pattern of investment in housing as part of a larger strategic framework is illustrated through large bank-related foundations, such as the Bank of America Foundation and the Wells Fargo Housing Foundation. Given their significant mortgage portfolios, their investments have usually targeted homeownership or asset building, or more recently, foreclosure issues. Often these bank-related foundations have focused on underserved communities, driven by the pressure to meet

\footnotetext{
${ }^{13}$ Jonathan Fanton, "Philanthropy Must Turn Attention to Housing Issues," Chronicle of Philanthropy 21.8 (Feb. 12, 2009); David Wertheimer, David Landers, "What Can Philanthropy Possibly do about Spiraling Housing Costs?," Philanthropy Northwest (Oct. 9, 2014), < https://philanthropynw.org/ news/what-can-philanthropy-possibly-do-about-spiraling-housingcosts >; Douglas Holtz-Eakin, Cameron Smith, Responding in Crisis: An Early Analysis of Foundations' Grantmaking During the Economic Crisis (May 2010), < http://www.philanthropy collaborative.org/documents/crisisreport_050610.pdf > .

${ }^{14}$ Observations are taken from an informal scan of the philanthropic field by Fred Karnas on behalf of the Kresge Foundation, June-October 2014.

${ }^{15}$ Donna Kimura, "Terwilliger Speaks Out on 'Silent Housing Crisis," Affordable Housing Finance (Nov. 23, 2014), <http:// www.housingfinance.com/affordable-housing/terwilliger-speaksout-on-silent-housing-crisis_o.aspx > .
} 
requirements under the Community Reinvestment Act (CRA). Non-industry-related foundations, such as the Surdna Foundation, with its interests in low-income communities, have focused on asset building, or on programs that deliver affordable housing at scale (Ford), or on urbanization generally (Rockefeller).

Much of the current housing-related investment is coming from more regionally focused foundations. For example, the Melville Charitable Trust has made significant contributions to supportive housing efforts in New England, as well as supporting national advocacy and policy efforts. Another example is the Conrad N. Hilton Foundation's support of housing for vulnerable populations in Southern California. At an even more focused scale are the program-related investments (PRI) of foundations, such as the Arizona Community Foundation's pre-development fund to support the front-end costs of planning and designing affordable housing projects, and the Meyer Memorial Trust's \$11 million dollar investment in Oregon to expand affordable housing.

\section{AFFORDABLE CARE ACT AND HOUSING: RENEWING THE CONNECTION TO HEALTH}

The passage of the Patient Protection and Affordable Care Act (ACA) in 2010 represents the era's most significant social legislation. It also presents several opportunities for restoring the connection between health and housing, and leveraging new philanthropic investment as well. The most significant of these opportunities, at least from the perspective of costs savings, is in housing-based services for chronic high utilizers of health care. In particular, homeless individuals, many now eligible for Medicaid in the 27 states (perhaps soon to be 28) and the District of Columbia that have expanded Medicaid, are expected to be among the costliest patients to treat. Already among the highest utilizers of health care, homeless patients are more likely to have mental health problems; chronic diseases, such as diabetes; and infectious diseases, such as tuberculosis. ${ }^{16}$

New research and program evaluations of treating homeless and other high utilizers of health indicate significant success in not only better chronic disease management, but also much lower utilization rates and at sharply lower costs. The key ingredient in the range of approaches is providing housing coupled with supportive services. A pilot program in Los Angeles, for example, that focused on the highest utilizers, resulted in a $71 \%$ reduction in emergency room visits, an $85 \%$ reduction in hospital readmissions, and an $81 \%$ reduction in hospital stays. ${ }^{17}$

\footnotetext{
${ }^{16}$ Martha Hostetter, Sarah Klein, "In Focus: Using Housing to Improve Health and Reduce the Costs of Caring for the Homeless," Quality Matters (Oct./Nov. 2014), < http://www .commonwealthfund.org/publications/newsletters/quality-matters/ 2014/october-november $>$.

${ }^{17}<$ http://shnny.org/research-reports/research/cost-savings >, $<$ shny.org/research/the-culhane-report48 > Hostetter, Klein, 2.
}

The success of these programs has led to a rising chorus among advocates to ask: "Should Obamacare help pay for housing?" The question is double-edged: Should Obamacare pay for housing-based services, such as supportive housing? And, should Obamacare pay for physical housing when it can be proven to reduce overall health costs? The answer from the Centers for Medicare and Medicaid Services (CMS) for the first question seems to be maybe, and for the second, no, at least for the time being. The interest in the health and housing connection, however, will only grow as more providers try to find ways to contain costs and improve patient outcomes. ${ }^{18}$

\section{MORE THAN HOMELESSNESS: THE MULTIPLE LINKS BETWEEN HEALTH AND HOUSING}

The second major opportunity for connecting health and housing is based in the evidence that substandard and unaffordable housing itself directly affects health. A brief issued in 2013, "Housing and Health: New Opportunities for Dialogue and Action," 19 by five executives and staff of public health and housing nonprofits, identified four major ways that housing is tied to poor health and called for a new dialogue between the health and housing sectors. Specifically, they identified these areas:

Housing quality-Substandard housing contributes directly to poor health, including lead poisoning, asthma, and injury. Poorly designed homes are a safety hazard for older adults; falls are one of the leading causes for hospitalization among seniors. The burden of substandard housing falls most heavily on low-income people of color (HUD, 2005). African American children, for example, are twice as likely to die from residential injuries than white children. Children of color also suffer from higher rates of elevated blood lead levels and asthma, which are both strongly related to older and substandard homes. These diseases not only impair physical health, but also contribute to poor educational outcomes and classroom attendance. $^{20}$

Affordability, residential stability, and crowding-In the U.S. today, there is a shortage of 7 million units of housing affordable to extremely low income families, not

\footnotetext{
${ }^{18}$ Alana Semuels, "Should Obamacare Help Pay for Housing?," Atlantic, (Oct. 27, 2014), < http://www.theatlantic.com/ business/archive/2014/10/should-obamacare-help-pay-for-housing/ $381885 /$ ?single_page $=$ true $>$.

${ }^{19}$ Jeffrey Lubell, Rebecca Morley, Marice Ashe, Linda Merola, Jeff Levi, "Housing and Health: New Opportunities for Dialogue and Action" (National Center for Healthy Housing, Feb. 2013), <http://www.nchh.org/Portals/0/HHFF_Housing and_Health_New_Opportunities.pdf $>$; The authors are (were) respectively executive directors of: Center for Housing Policy; National Center for Healthy Housing; ChangeLab Solutions (Linda Merola was senior staff attorney); and Trust for America's Health.

${ }^{20}$ Lubell, Morley, Ashe, Merola, Levi, 3-5; Nanhua Zhang, Harolyn Baker, Margaret Tufts, Randall Raymond, Hamisu Salihu, Michael Elliott, "Early Childhood Lead Exposure and Academic Achievement: Evidence From Detroit Public Schools, 2008-2010," American Journal of Public Health (Mar. 2013), e72-e76.
} 
to mention the challenges facing other low- and middleincome renters. ${ }^{21}$ The lack of affordable housing, in combination with the challenges faced by vulnerable populations, has a significant impact on health. In addition to the draconian choices low-income renters must sometimes make between food, health care, or rent, the residential instability and crowding that are associated with housing unaffordability have also been linked to chronic disease, stress and poor child health, and educational failure. $^{22}$

Physical neighborhood attributes-The physical design and make-up of a neighborhood has health impacts. Attributes such as proximity to traffic, recreational areas, walkability, mixed-use development, and access to fullservice grocery stores characterize what constitutes a healthy neighborhood. Further, these attributes are interrelated and mutually reinforcing. Low-income communities frequently lack these amenities, and also suffer from an inequitable and excessive exposure to toxicants and pollution. These contribute to higher rates of chronic diseases such as asthma, cancer, and heart disease. ${ }^{23}$

Social and community attributes-These attributes include: neighborhood security, social cohesion, residential segregation, and concentrated poverty. Fear of crime and violence in neighborhoods can discourage physical activity and recreation, and heighten stress. The loss of social cohesion or connectedness in a community has been linked to lower life expectancies, and also to specific health conditions. Conversely, high levels of community trust can improve health and safety and reduce crime. $^{24}$

Segregated housing has been linked to poorer health outcomes. Segregation, of course, has multiple consequences: low social mobility, proximity to undesirable land uses, substandard housing, poor transit choices, and low performing schools, to name a few. These patterns of segregation by race and class, furthermore, were developed through decades of racially motivated and biased housing policies, and land use decisions. ${ }^{25}$

These four major links between health and housinghousing quality, affordability, and physical and social

\footnotetext{
${ }^{21}$ National Low Income Housing Coalition.

${ }^{22}$ Lubell, Morley, Ashe, Merola, Levi, 5-7.

${ }^{23}$ Lubell, Morley, Ashe, Merola, Levi, 7-9; Robert D. Bullard, Glenn S. Johnson, Angel O. Torres. Environmental Health and Racial Equity in the United States: Building Environmentally Just, Sustainable, and Livable Communities (APHA Press, 2011), 52; Paul Mohai, Byoung-Suk Kweon, Sangyun Lee, Kerry Ard, "Air Pollution Around Schools Is Linked To Poorer Student Health And Academic Performance," Health Affairs (May 2011), 852-861; R. Hickey, J. Lubell, S. Morse, "Losing Ground: The Struggle of Moderate-income Households to Afford the Rising Costs of Housing and Transportation," Washington DC: National Housing Conference and Chicago: Center for Neighborhood Technology, 2012, <http://www.nhc.org/media/files/losing_ground_ 10_2012.pdf $>$.

${ }^{24}$ Lubell, Morley, Ashe, Merola, Levi, 9-10.

${ }^{25}$ Richard Rothstein, "The Making of Ferguson," American Prospect (Fall 2014), 47-53; Stoloff, 6-9; D. Williams, C. Collins, "Racial Residental Segregation: A Fundamental Cause of Racial Disparities in Health," Public Health Reports 116 (2001), 409-411.
}

neighborhood attributes-indicate strongly that improved housing and neighborhood environments could potentially lead to significant reductions in health disparities. But these improvements will require a deeper, more prolonged cross-sectoral and multi-disciplinary engagement. A new framework that can bridge the sectors and systems will need to be developed.

\section{BEYOND THE AFFORDABILITY PARADIGM: HOUSING AS PLATFORM}

Housing affordability represents both a national and global crisis. The McKinsey Global Institute reports that 330 million urban households around the world lack decent housing and affordable housing. Of these, 96 million are financially overstretched and 235 million live in substandard homes. ${ }^{26}$ But this data suggests that the housing problem is actually much bigger than just financial.

The growing evidence, especially on the multiple health impacts of housing, strongly suggests a need to move beyond a framework focused predominantly on affordability. Leaders in the field have raised the need for a broader framework, which includes affordability at its center but also sees housing as a tool for improving the quality of life for residents in multiple ways. Early in the Obama administration, the Department of Housing and Urban Development embarked on the creation of a strategic plan to guide the agency's efforts from 2010 to 2015. For the first time in HUD's history, included among the five goals of expanding homeownership and affordable rental housing, building sustainable communities and improving agency operations, was a new goal focused on better using the resource housing brings to individuals and communities. The goal, entitled "Utilizing Housing as a Platform for Improving Quality of Life," called for HUD to develop partnerships at the federal, state, and local levels to use its housing resources better to "deliver a wide variety of services to improve the quality of life of its residents and the surrounding community." Imbedded in the goal were sub-goals focused on improving health and educational outcomes, economic security, and public safety, as well as providing increased support for vulnerable populations. This strategic goal signaled a significant change in policy and perspective at the federal level and throughout the network of HUD supported housing and the communities in which that housing was located.

Ben Hecht, who leads Living Cities, a collaborative of major foundations and financial institutions, also noted the changing view of housing. "Policymakers are...no longer relying on housing as a panacea for poverty." The changing urban housing market, including low demand for homeownership, shrinking property values, and widening impacts on both low and middle classes, Hecht

\footnotetext{
26" A Blueprint for Addressing the Global Affordable Housing Challenge: Executive Summary," McKinsey Global Institute (Oct. 2014).
} 
writes, "is serving as an opportunity to rethink our approach to rebuilding communities." 27

A 2010 survey of foundation leaders revealed increasing interest and emerging investments in housingas-a-platform, but without a clear consensus around the model. The researchers found that, "housing as platform is interpreted in many ways, and each interpretation suggests different grantmaking approaches." The confusion or heterogeneity of interpretations has hindered further development of public-private partnerships to develop this work. ${ }^{28}$

Foundations whose primary focus is health, for example, have largely approached this housing question through community development as a platform to tackle the root causes of poor health. ${ }^{29}$ Foundations such as the Robert Wood Johnson Foundation, the California Endowment, and the Kresge Foundation, where we work, have focused, for example, on issues like healthy housing, access to healthy foods, walkable neighborhoods, and pollution. The rising interest in healthy community development is resulting in new partnerships between health funders and community development financial institutions (CDFIs), for example, and new investments in comprehensive development models such as Purpose Built Communities. Kresge has used program related investments (PRIs) to leverage private investments in low-income housing tied to health care and other related services. The MacArthur Foundation, whose principal focus is not on health, nevertheless has made major contributions to the field through its policy research. ${ }^{30}$

\section{RE-CONNECTING HOUSING AND HEALTH: HOUSING AS A MULTI-LEVEL PLATFORM IN AN ERA OF HEALTH SYSTEM REFORM}

The differing and diverse interpretations of housing as a platform would suggest it is problematic as the basis for an organizing framework. But we believe that-given the multitude of health consequences from housing-health itself could be the glue that binds the interpretations together. The reforming health care environment has become fertile ground for housing-based solutions for health improvement, especially for improving health outcomes for vulnerable populations. The ACA has

\footnotetext{
${ }^{27}$ Ben Hecht, "The State of the City: 5 Trends Impacting American Cities," Living Cities (June 2013), <https://www .livingcities.org/blog/288-announcing-the-release-of-the-stateof-the-cities-5-trends-impacting-america-s-cities $>$.

${ }^{28}$ Riley, Kraft, 11-12.

${ }^{29}$ Samantha Braunstein, Risa Lavizzo-Mourey, "How the Health and Community Development Sectors Are Combining Forces to Improve Health and Well-Being," Health Affairs (Nov. 2011), 2042-2051; Grantmakers in Health, Health Philanthropy: New Players and New Approaches (Nov. 2013), < http://www.gih.org/ Publications/StrategicDetail.cfm?ItemNumber $=5892>$; $\quad<$ http:// purposebuiltcommunities.org/ > ; <ttp://healthyfuturesfund.org $>$; $<$ http://www.macarthur.org/programs/how-housing-matters/ strategy/>.

${ }^{30}$ Judith Bell, Larry Cohen, "How a Group of Philanthropists Broke the Mold and Unlocked the Power of Collaboration," National Civic Review (Winter 2013), 40-42.
}

spurred opportunities to make specific and explicit connections between the health care, public health, and housing sectors. But where the original housing-health alliance was focused on the prevention of infectious disease, the new alliance would be principally aimed at managing and preventing chronic disease, including mental illness and substance abuse.

The new alliance also has the potential to restore or elevate the connection between decent and affordable. The growing evidence underscores the deep interconnectedness between unaffordability and health-from the effects of substandard housing on child health to the impacts of displacement on mental well-being and educational and economic opportunity. The health sector also brings new tools and solutions, and potentially, resources for improving unhealthy homes and developing and preserving new units. These tools include policy innovations such as proactive rental inspection, a model national healthy housing standard, and potential Medicaid waivers that can apply to some environmental remediation in homes. ${ }^{31}$ Further, health providers are recognizing the potential of older tools, such as housing code enforcement, to address chronic disease "hotspots" in older neighborhoods. ${ }^{32}$

We see the emerging solution sets and innovations coalescing around three distinct approaches to housing as a platform for improving health and quality of life. We do not claim that these three constitute a comprehensive model for housing as a platform, but rather represent imminent, actionable, and investable opportunities emerging in a historic period of health reform. These also reflect a potential alignment of interests between the housing and health sectors. The three approaches are:

1. Housing as a service delivery portal for high-risk, high cost populations: Housing serves special populations, requiring different levels of in-home 24/7 care and support.

2. Substandard housing as target for prevention for at-risk populations: Treatment and intervention for management of chronic disease, or prevention of injury, includes specific home and housing remediations. (e.g., removal or mitigation of lead

${ }^{31}$ ChangeLab Solutions, Model Proactive Rental Inspection Ordinance (July 2014), <http://changelabsolutions.org/sites/ default/files/Healthy_Housing_Proactive_Rental_Inspection_ FINAL_20140421.pdf > ; American Public Health Association, National Center for Healthy Housing, National Healthy Housing Standard (June 2014), < http://nchh.org/Policy/NationalHealthy HousingStandard.aspx > ; National Center for Healthy Housing, Healthcare Financing of Healthy Homes: Findings from a 2014 Nationwide Survey of State Reimbursement Policies (Nov. 2014), <www.nchh.org/Resources/HealthcareFinancing/Snapshot .aspx $>$.

${ }^{32}$ Andrew Beck, Bin Huang, Raj Chundur, Robert Kahn, "Housing Code Violation Density Associated with Emergency Department and Hospital Use by Children with Asthma," Health Affairs (Nov. 2014), 1993-2002; Megan Sandel, Mark Hansen, Robert Kahn, Ellen Lawton, Edward Paul, Victoria Parker, et al., "Medical-Legal Partnerships: Transforming Primary Care by Addressing the Legal needs of Vulnerable Populations," Health Affairs (Sept. 2010), 1697-1705. 
exposure, asthma triggers, or safety hazards; also, weatherization, when coordinated with remediation $^{33}$ ); or policy solutions and regulation.

3. Housing development as anchor for healthy, opportunity rich communities: This includes comprehensive models of community and neighborhood development, such as Choice Neighborhoods or Purpose Built Communities.

Figure 1 describes the different housing-based interventions/ developments and the associated populations and potential financing sources. (Among the possibilities for financing is the use of pay-for-performance contracts, which can leverage private investments in health promotion programs. ${ }^{34}$ ) The arrows indicate the continuum of service/ intervention from individual patients to population or community level health, and from highest cost (treatment) to lowest costs per capita (prevention).

The figure above does not mean to construe that each level is easily linked to the next, but to draw attention to how the different housing platforms align with high priority concerns of the health sector. The platforms also should not be seen as displacing or superseding efforts to increase housing affordability and availability (stock). But these bring new tools and partners to the table, and thereby raise the potential for a broader consensus around the need for a systematic and comprehensive solution to the housing crisis. This consensus, however, will not develop without a serious new engagement between the housing and health sectors.

\section{HEALTH AND HOUSING: THE EMERGING ROLES FOR PHILANTHROPY}

Philanthropy can play an important role in reconnecting these sectors due to its ability to take the long view and to take measured risk, its flexibility, its capacity to act as a bridge between sectors, and support community voice. We describe some specific roles here.

\section{Build the evidence base}

The MacArthur Foundation's recent focus on research has provided significant support for evidence-

\footnotetext{
${ }^{33}$ The Green and Healthy Homes Initiative is a project of the Baltimore, MD based Coalition to End Childhood Lead Poisoning. The initiative is an effort to lead national efforts to integrate lead hazard control, healthy homes, weatherization and energy efficiency in low-income communities. <http://www .greenandhealthyhomes.org/about-us/history-and-mission $>$.

${ }^{34}$ Pay for performance, also known as pay for success or social impact bonds, is essentially a performance based contract between a provider of services, a payor (usually government or other institutional source), and private investors, including foundations. This is emerging as a model for testing the effectiveness of social programs for saving costs over a specified period of time for specific populations. Investors and providers bear the risk of such programs not meeting their cost-savings targets, instead of government. $C f$. Ian Galloway, "Using PayFor-Success To Increase Investments In the Nonmedical Determinants of Health," Health Affairs (Nov. 2014), 1897-1904.
}

based practice and policy reform both broadly on housing-related issues and specifically at the intersection of health and housing. Their efforts have reinforced the need for continued research support to answer such questions as:

- How can housing be a platform for outcomes beyond shelter (e.g., health, education, child welfare involvement, etc.)?

- How can health resources be deployed differently to account for the health impacts of safe, decent, affordable housing?

- To what extent does housing mobility yield short and long-term health benefits?

- What are the costs/benefits (state and federal savings realized) and health and income impacts of a variety of housing and services interventions?

\section{Change the narrative}

Building public awareness of the significant need for affordable housing in the nation, as well as the health impacts of the lack of affordable housing, is a prerequisite for policy change. Supporting well-crafted public awareness efforts at the local and national levels can ultimately impact service delivery and public policy. For example, a number of funders have recently underwritten the Home Matters campaign lead by the National NeighborWorks Association to highlight the impact housing has on various aspects of daily life, from health to education, and beyond.

\section{Advance policy change}

Although foundations often shy away from supporting advocacy, the support of efforts to press for policy change that recognizes the impact of housing on health is an important role they can play. As an example of how foundations can help positively shape public policy in the health and housing arena, the Melville Charitable Trust and the Harry and Jeanette Weinberg Foundation have played an important role around the reframing of HUD's 811 program serving persons with disabilities.

\section{Support community engagement}

Closely linked to advocacy, community voice is a fundamental element of a new housing agenda. The history of low income and public housing, beginning with the nineteenth century, is rife with examples of top-down approaches that did not incorporate community residents as partners. While well intentioned, these efforts often resulted in concentration of poverty, loss of social cohesion, and ultimately, further abandonment. ${ }^{35}$ Philanthropy is vital to support community-driven efforts not only in direct housing related investments and land use planning, but also in issue

\footnotetext{
${ }^{35}$ Stoloff, 9-10; Frank, 23.
} 


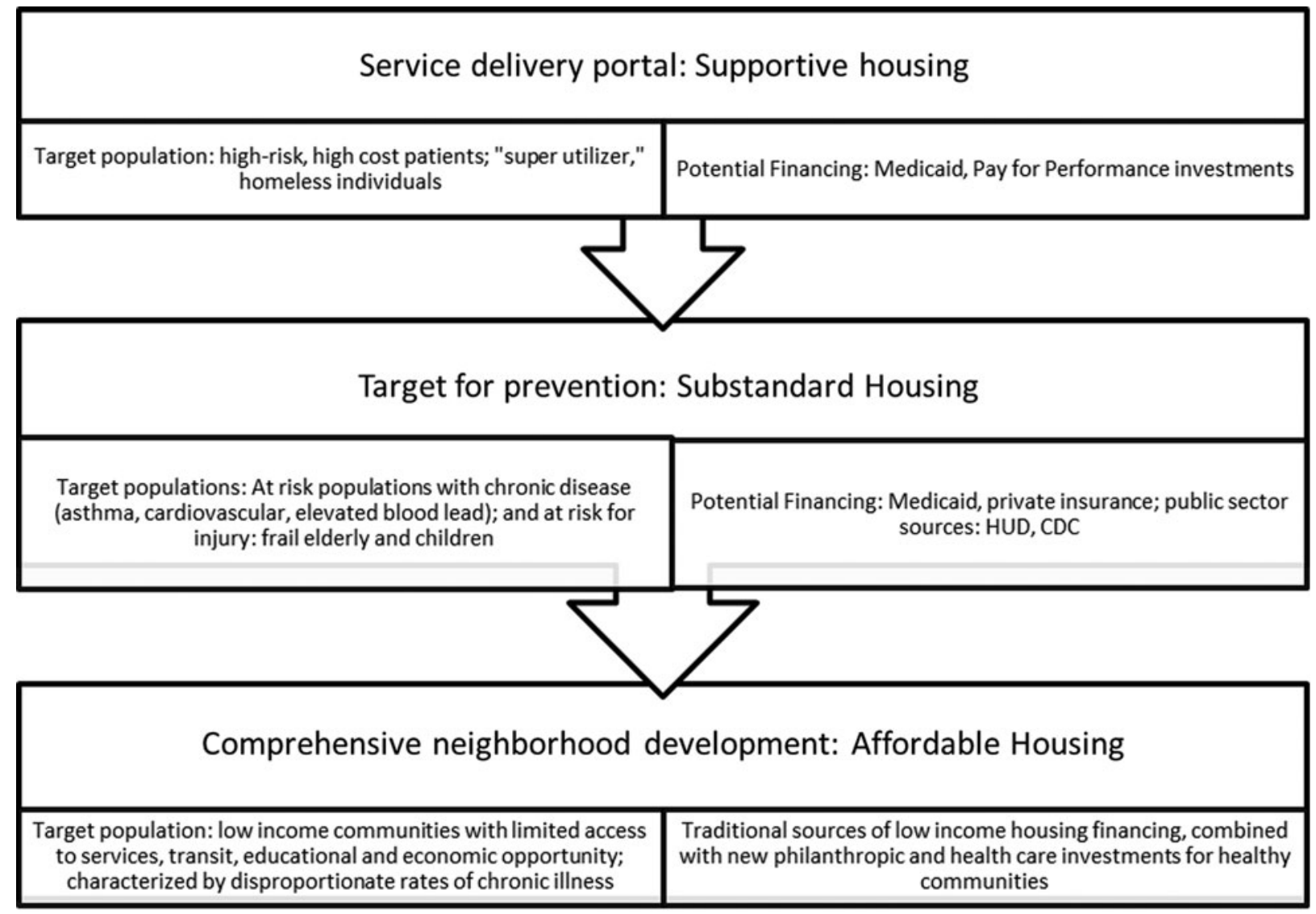

FIG. 1. Housing-based interventions/developments with associated populations and potential financing sources.

and problem identification, holding government accountable, and communicating community concerns. ${ }^{36}$

\section{Build bridges across sectors}

Philanthropy's convening role is a particularly important tool in bringing together two very disconnected systems, health and housing. Connecting representatives of the two systems to learn each other's language, understand their fiscal and programmatic challenges, and craft solutions that build on both systems strengths can be a powerful tool for reform. For example, recent support by the Kresge Foundation of a convening sponsored by Stewards for Affordable Housing for the Future brought together leading national housing non-profits with a number of Managed Care Organizations to discuss ways to work together to address the issue of high utilizers.

\section{Accelerate innovation}

Support for innovative approaches that connect health and housing is critical for advancing the field. For exam-

\footnotetext{
${ }^{36}$ Manuel Pastor, Rachel Morello-Frosch, "Integrating Public Health and Community Development to Tackle Neighborhood Distress and Promote Well-Being," Health Affairs (Nov. 2014), 1890-1896.
}

ple, piloting ways to better align funding sources among the various housing and health programs is one area that needs support. Another is supporting efforts to better direct resources like Medicaid to services in supportive housing as the Bill and Melinda Gates Foundation is doing in the state of Washington. Similarly, communities need support to prepare effectively to meet the needs of persons with greater acuity as persons with disabilities are given the opportunity to move from institutional settings to the community as a result of policy changes promoting more integrated settings for that population.

\section{Build capacity}

Better connecting two relatively disconnected systems requires enhanced capacity in both health and housing entities. Staff training on system language, restructured financial offices to deal with different billing requirements, a better understanding of reimbursement cash flow, and new technical skills for front line workers are among the capacity needs of health and housing organizations that funders can help support.

\section{CONCLUSION}

The reforming health care system is creating opportunities for innovation that puts more focus on prevention 
of chronic disease than its treatment. Since housing affects health in multiple ways, especially for low-income residents and communities, there is a growing recognition that housing can be a platform for improving their health and wellbeing. The three principal platforms are: housing as a service delivery portal (supportive housing); substandard housing as a target for prevention; and affordable housing as an anchor for healthy community development. Each of these platforms represents emerging areas of interest for the health care sector and philanthropy and housing. Philanthropy has the opportunity to re-assert its historic role in bridging these sectors and fostering the interactions and policies that can break down the silos that now separate them.

\section{AUTHOR DISCLOSURE STATEMENT}

The authors have no conflicts of interest or financial ties to disclose.

Address correspondence to: David D. Fukuzawa

The Kresge Foundation 3215 W. Big Beaver Rd. Troy, MI 48084

E-mail: ddfukuzawa@kresge.org 